\title{
Understanding homelessness through poetic inquiry: Looking into the shadows
}

\author{
Lee-Ann Fenge ${ }^{1}$, Wendy Cutts, ${ }^{2}$ \\ and Jon Seagrave aka Jonny Fluffypunk ${ }^{3}$
}

\begin{abstract}
Homeless people often have multiple and complex needs resulting in deep social exclusion. Homelessness research represents a contested arena and one in which it is important to place the human experience of homelessness at the heart of the process. This paper reports on the Seldom Heard Voices project which used poetic inquiry as a qualitative research tool to examine the experience of homelessness. A performance poet, a group of homeless people attending a homeless hostel, and academics from social science backgrounds worked together to explore the lived experience of homelessness creating insights into wellbeing, identity, and belonging. This paper presents an overview of the project and considers how 'poetic' writing can engage seldom heard voices, providing a context for understanding the lived experience of homelessness through the words of participants, alongside the reflective narrative of the poet working with them. The project methodology is considered and the themes arising from two poems and the poet's narrative is discussed.
\end{abstract}

Keywords: homelessness; social services; poetic inquiry; arts-based research

1. Professor of Social Care

2. Senior Lecturer Faculty of Health and Sciences, Bournemouth University

3. Freelance Poet

Address for correspondence: lfenge@bournemouth.ac.uk

Date of first (onlne) publication: 2nd October 2018 


\section{Introduction}

Homeless people often exist on the fringes of society, and although they are known to exist as a 'social problem' and are increasingly visible on the streets, their lived experiences and daily challenges often remain hidden from view. Those experiencing homelessness often have multiple and complex needs resulting in 'deep social exclusion (Fitzpatrick, 2007). They may become treated as objects in public space subject to harassment, violence and abuse (Farrugia, 2011). They are excluded not only in economic and social terms, but also in terms of how they are able to participate in the process of policy and research about homelessness (Norman and Pauly, 2013). It is therefore important for research to address the ways in which the voice of homeless people is included within the research process.

Social workers have a responsibility to 'promote the recognition and protection of the human rights of people experiencing homelessness' (Aykanian and Lee, 2016, p. 184). To achieve this aim, it is important not only to adhere to social work values underpinned by social justice which upholds the dignity of all people (IFSW, 2012), but to have a person-centred understanding of the lived experience of homelessness. The increasing growth in officially estimated numbers of rough sleepers in the UK, up by 132 per cent since 2010 (Fitzpatrick, et al., 2017), means that more than ever social work agencies and professionals need increased understanding of the challenges faced by homeless people. This paper discusses how participatory poetic inquiry offers a useful approach to engage with homelessness, promoting improved insights into the 'lived' experience of homelessness and the challenges faced by homeless people. Discussion will be illustrated by reference to the Seldom Heard Voices project which used poetic inquiry with a group of homeless people $(\mathrm{n}=15)$ recruited via a local homeless hostel in the South West of England.

\section{Homelessness as a 'hard to reach' research topic}

Undertaking research on homelessness has been described as complex as it is 'a contested, and politically and morally charged enterprise' (Farrugia and Gerrard, 2016, p. 270). The contested nature of homelessness pivots around whether homelessness is seen to result from individual factors or structural factors (Farrugia and Gerrard, 2016), or as an interaction between both (Fitzpatrick, 2005). This complexity has led one researcher to describe homelessness research as 'still uncomfortably close to being a conceptually inconsistent mess' (Pleace, 2016, p. 25). The way in which homelessness is viewed within society is also mediated by welfare systems which construct notions of agency and responsibility. For example, the impact on how certain groups are depicted as deserving or undeserving of assistance has been linked to a punitive turn in welfare systems, influenced by neoliberalism and a 
focus on individual responsibility (Wacquant, 2010). This is evidenced by a growth in the conditionality of welfare benefits in the UK since 2012, which increase the challenges faced by homeless people (Reeve, 2017). Such changes in welfare policy, and the growth in strict eligibility criteria, therefore serve 'as a punitive/disciplinary measure against the socially marginalised' (Reeve, 2017, p. 66).

Rather than adopting an approach to the project focused on normative distinctions between 'the homeless' and 'everyone else', the Seldom Heard Voices project used creative means to communicate the experience of homelessness. This approach hoped to evoke an emotional response from those accessing the poetry, helping to construct alternative forms of representation to promote dialogue and understanding (Jones, 2006). This offers a balance to the 'orthodoxy' of homelessness research by delivering 'a renewed focus on the experiences, understandings, subjectivities and activities of those who are homeless' (Farrugia and Gerrard, 2016, p. 280).

Homeless people encounter multiple exclusions including stigma and discrimination which may make them hard to reach in terms of both research and practice (Liamputtong, 2007). Those described as hard-to-reach are generally socially invisible and this poses barriers to recruitment into research (Faugier and Sargeant, 1997), particularly in terms of identifying potential participants (Ellard-Gray, et al., 2015). Our approach aimed to overcome this challenge by adopting facility-based sampling (Shaghaghi, et al., 2011), working in partnership with a homeless hostel as gatekeeper to potential participants. A limitation of using a 'facility' as a gatekeeper is that the project only reaches those individuals who use the services offered by the hostel. This might be deemed a weakness in that the sample represents lived experiences which occur within a policy response, in as much that hostels have been constructed to offer an intervention to deal with homelessness, and individual identities have been forged within this environment. This may limit insight into a wider appreciation of what homelessness means to those who prefer to avoid contact with organisations offering support to homeless individuals.

As with any research with so called 'hard to reach' populations, certain individuals may remain in the 'half shadows' through choice. Even when using participatory methods, it is important for researchers to acknowledge that some individuals will choose to remain hidden from view. Despite the sampling limitations resulting from facility-based sampling, it did allow us to communicate directly about the project with those who used the hostel. As sessions took place within the hostel, it also provided a familiar venue in which to hold the creative workshops.

Another challenge in undertaking research with 'hard to reach' homeless participants was linked to the chaotic life styles of some which resulted in attrition and sporadic attendance at the fortnightly poetry workshops. High drop-out rates and poor attendance at research sessions have been identified as common features in research with certain vulnerable groups (Bonevski, et al., 2014; Johnsen, et al., 2008). Sporadic attendance was an issue for the Seldom Heard Voices project. Although fifteen individuals took part in the workshops over the course of the ten 
sessions, attendance was often intermittent leading to challenges for the facilitator of the sessions. This will be considered in more detail later in the paper. To increase attendance sessions took place at a time when food was available in the hostel as it was felt that this might act as an incentive to participants to stay for the poetic inquiry sessions. Although this did help, issues linked to mental well-being made regular attendance a real challenge for some individuals.

\section{Background to The Seldom Heard Voices Project}

The Seldom Heard Voices project built on the poetic methodology employed in the authors' previous research with other seldom heard groups (Fenge, et al., 2016; Hodges, et al., 2014). The aim of the project was to provide insights into the everyday lived experiences of homeless people, using their own words and language captured through participant poetry. Our approach was focused on providing in-depth, nuanced information about the nature of homelessness and the 'multiple exclusions' homeless individuals experience (Fitzpatrick, et al., 2013). Our use of participatory participant poetry, written by either single authors or as a collaborative group poem, was based on using poetic inquiry to uncover or create new knowledge. Participant written poetry can create insights using language where exploration of feelings and experiences can occur (Furman, et al., 2012).

This approach is grounded in social justice through its participatory approach, which engages directly with the experiences and feelings of homeless people to explore issues related to family, identity and marginalisation. It offers a means to empower and promote the voices of those who are historically silenced or marginalised (Bagley and Castro-Salazar, 2012), enabling them to frame the issues that are important in their lives. By using such methods we sought to address the challenge offered by Pleace (2016, p. 37) that homelessness research should 'acknowledge, respect and understand the human beings at the heart of homelessness'. This also links with international social work values which seek to recognise all aspects of a person's life (IFSW, 2012).

Participants in the Seldom Heard Voices project were all recruited via a local homeless shelter in the South West of England using facility-based sampling. This hostel caters for 40 residents who stay between a minimum of one night to a maximum of six months at the hostel. This was a convenience sample of homeless men and women who used the hostel and there were no specific inclusion/exclusion criteria. Fifteen participants attended the ten workshops, although attendance was sporadic. Most participants were male although two women attended occasional workshops. Hostel residents move through the hostel and local area in an ephemeral manner.

The project was a collaboration with the shelter, and the project was funded by Bournemouth University Impact Acceleration Fund. Most participants had multiple 
and complex needs linked to the category of 'deep social exclusion' described by Fitzpatrick (2007). This type of multiple exclusion homelessness (MEH) is defined in the following way Fitzpatrick, et al. (2013, p. 149):

People have experienced MEH if they have been 'homeless' (including experience of temporary/ unsuitable accommodation as well as sleeping rough) and have also experienced one or more of the following other 'domains' of deep social exclusion: 'institutional care' (prison, local authority care, mental health hospitals or wards); 'substance misuse' (drug, alcohol, solvent or gas misuse); or participation in 'street culture activities' (begging, street drinking, 'survival' shoplifting or sex work).

Using poetic inquiry allows new insights into the intersections of various exclusionary factors which frame homeless experience and individual identity.

\section{Rationale for arts based research}

Arts-based research and arts-informed inquiry were developed to challenge the 'limitations and oppressive features of traditional scientific research, opening spaces for experimentation of alternative approaches' (Butterwick, 2002, p. 243). These creative methodologies can also facilitate the formation of identities for people experiencing oppression or marginalization (Moxley, 2014), and this may be an important consideration when undertaking research with homeless people. The opportunity to engage in arts-based projects may support homeless people to represent the issues they face in their daily lives, including identity issues, feelings of belonging and feelings of being 'othered'. The Seldom Heard Voices project worked with a performance poet, and performance poetry can be viewed as a form of social activism. The performance poet was pivotal in creating an artistic space which offered opportunities for expression to people who do not readily fit into normative structures (Rawdon and Moxley, 2016).

The value of an arts-based approach is that it develops understanding of both participant and researcher experience (McNiff, 2008). Different arts-based methodologies have been employed to engage with the 'voice' and experience of homeless participants in recent years. For example, Clover (2011) used a feminist arts-based participatory research project with a group of homeless women. Others have used arts based poetic approaches when working with homeless groups to represent the interactions which take place between researchers and young homeless participants (Oppong Asante and Meyer-Weitz, 2015; Finlay, 2000). Poetry may therefore be used as a tool within qualitative research to understand and portray the lived experiences of individuals, and to 'create new spaces for understanding the disparate images of social constructions and lived experiences' (Finlay, 2015, 
p. 508). Despite a growing visibility in the research literature it has been suggested that poetic inquiry struggles for recognition and 'is yet to be fully established and accepted by the mainstream qualitative research community as a legitimate approach' (Bishop and Willis, 2014).

Arts based research has been classified as occurring across three major categories: research about art, art as research, and art in research (Wang, et al., 2017). Using this classification it appears that the Seldom Heard Voices project, and indeed the authors' wider body of research using participatory arts based approaches, fits the description of art in research. Participant poetic inquiry is the use of art in research in which 'art is actively applied by participants and/or artist-researchers as a creative process in one or more phases of a research process studying social and behavioural science phenomena' (Wang, et al., 2017, p. 15). Participant poetry is treated as data (Lahman. et al., 2010), and as such the words and language used by participants directly allows exploration of feelings and experiences (Furman, et al., 2012). This approach is different to other forms of poetry used in qualitative research in which researchers use words or themes from research interviews to generated poetry. The latter is referred to by a variety of terms such as found poetry (Sjollema, et al., 2012), poetic transcription (Clarke, et al., 2005; Glesne 1997), or poetic inquiry (Butler-Kisber, 2004).

The participatory nature and openness of art in research offers a medium that allows research participants to 'communicate' with researchers about their situation, whilst also being a vehicle for dissemination of research findings through the generation of artefacts. In this project the artefacts are in the form of individual and group poems. It is important for those engaging with poetry as data to recognise that 'traditional measures of validity are not appropriate criteria for judging research poems' (Hesse-Biber and Leavy, 2008, p.13).

\section{Aims and objectives}

The project ran through a series of poetry workshops $(n=10)$ facilitated by a performance poet known as Jon Seagrave AKA Jonny Fluffypunk. He had previously worked with the researchers on earlier projects with other seldom heard groups such as young people with disabilities and older people in sheltered housing. The aim of the workshops was to utilise a range of creative means to assist participants to express their lived experiences of homelessness, including issues related to identity, belonging and otherness.

From the outset we were mindful to create an atmosphere in the workshops which would reinforce human connections. After the first session, which both researchers attended along with the performance poet, we quickly decided the presence of all three of us was overwhelming and potentially oppressive for participants. We agreed 
that the sessions would be facilitated by the poet with support from a member of the hostel staff. This was important to try to 'normalise' the activity within the day to day running of the hostel. The approach taken by the poet stressed connectivity through positive human emotions, focusing on communicating through 'a good personal story' (Thomas, et al., 2017)

\section{Research findings}

The discussion of research findings will be illustrated by discussion of two group poems, and we approach the participant poetry as data (Lahman, et al., 2010). Alongside this there is consideration of the poet's reflective account of working on the project. These two perspectives give insights into key themes which are important in developing understanding of homeless people's lives, as well as consideration of some of the challenges involved in the project.

\section{This is The Place: A Bournemouth Poem - Group Poem}

(written in the style of a poem by Tony Walsh which was shared with the group)

This is the place

where I am.

This is the place

where you meet your circle

in the square at the bottom of the triangle.

This is the place

where it's like a war,

and most of the time

it seems we get only shrapnel

This is the place

where beggars get contributions

be it silver or gold

Where a tenner drop

is like a diamond

This is the place

where people follow their own shadows

in endless circles

where you are alone in the crowd,

where you are either non-existent

or all eyes are on you

the place of many hiding places, 
some in full view

This is the place

of sun, sea and skag

of twenty three deaths

in just ten weeks

of dole offices that don't give a shit

and buses that just drive past

This is the place

of millionaires and Tory conferences

This is the place

where my children and grandchildren are

and that makes it the most special place

This is the place

you are meant to be.

\section{Some People - Group Poem}

(written in the style of a poem by Rita Ann Higgins which was shared with the group)

Some people know what it's like

To have your mum sleep with Prince Valium on a daily basis

To have half your possessions in Cash Converters

To have the godsend of finding a quid in your pocket that you'd forgotten

To roll out of bed and have the thrill of finding a few quid underneath

To never hold the queen's head for more than a few hours

To know the ruthlessness of the DWP

To know getting into the queue for the queue for the queue

To loathe the sound of Vivaldi's Four Seasons

To make the mistake of thinking that the clue is in the name 'Benefit Enquiries'

To spend 49 minutes on the phone to finally get through

to a girl who tells you to go to the Job Centre anyway cos she can't help you

To look at the food and think where did they get that from?

To choose good food over accommodation

To be bailed out by the masons when your pitch crashes

To have people show concern then not even listen to your answer

To have people show concern then not even listen to your answer

To have people show concern then not even listen to your answer

Some people know what it's like

To have a hard mattress like a prison mattress

and three quilts on top to make it comfortable

To dread asking questions and prolonging the anxiety- 
will he lend me a tenner or tell me to fuck off?

To be a slave of time's laws

To feel the burden of free time and to dread empty hours

To be wealthy of time and non-wealthy of funds

To have PGT- pre giro tension

To have reliability increase tenfold on giro day

To have Groundhog Day syndrome

To go to sleep and wake to the same conversations.

And other people don't

[Clarification of terms used in this poem: 'Queen's Head' refers to the monarchs head on bank notes and coins, 'DWP' refers to the Department for Work and Pensions, and 'PGT' is a pun on PMT (pre-menstrual tension) and refers to the feelings that build up prior to a benefits cheque being cashed]

\section{Extracts from poet's reflective diary}

The following extracts from the performance poet's reflective diary demonstrate both the challenges and rewards of undertaking research with homeless people. Names have been changed to ensure anonymity.

Various people who had been keen to take part didn't show, which is apparently par for the course. Was a bit disappointed Percy didn't come. The project worker reckoned he'd been really looking forward to it all week, but then had some sort of mood shift yesterday and disappeared.

Around six or seven passed through our ranks today- it's difficult to be exact because people came and went all the time, and I had my hands full trying to keep those who were there at any one time engaged... I showed some poetry films, which were hotly debated (John Cooper-Clarke came out top). We then did an 'identity' piece based on Rita Ann Higgins' 'Some People', which is a great poem to use with marginalised groups as it is a strong, defiant, self-assertive piece from someone at the bottom of the pile.

Well, we got a poem out of it! This is easier said than done. The session was very lively, and every line of the poem was hotly debated.

There was continuous disruption, which slows everything down, but this is par for the course. Frankie, for instance, -will suddenly be 'called away' by someone just in the middle of delivering a lyrical gem, and disappears. This happened several times. Each time someone new appeared, proceedings had to be explained. Certain personalities- such as Martin-, seem to delight in being controversial

And the level of engagement, once participants are there, is very good (disruptions aside); there is very lively debate around the topics and lots of helpful comments to help shape phrasing and lines. People take real pride in a good turn of phrase and 
are quite keen to please.

Arrived to find a group waiting! Lovely surprise. It was great having an attentive group to work with- it's been a while! They responded very well to the photo prompt; it provoked very animated discussion and a good selection of 'response' pieces, all of which seemed to have a common 'heavy' import- a lot of good/evil, dark/light symbolism. There were lots of linking references to the 'darkness' the participants unanimously feel to be a core part of their life experiences.

The pressure on me just to keep them present and engaged often precludes me being able to focus on individuals and wheedle something more satisfying out of them, lest the others get distracted, down pens and disappear. Today we only lost one.

The following section discusses the themes and issues arising from both the poetry and reflective diary notes.

\section{Discussion}

Both poems give insight into the subjective experiences and feelings of those living on the streets, including the multiple complexities of daily life and the deep social exclusion which result from experiencing multiple challenges (Fitzpatrick, 2007).

These narratives do not represent statistics about homelessness or attribute structural or individual roots to homelessness. They illustrate issues related to belonging and being 'othered', and highlight how being displaced changes a person's sense of self, place, and belonging (Vandemark, 2007). For those existing in the half shadows, place and space present stark choices which take place in a context of 'warfare and shrapnel', where choices pivot around eating or accommodation. The lived experience is central in these descriptions, and the reflective account from the poet facilitating the poetry sessions describe how 'darkness' is unanimously felt to be a core experience.

Space in these poems depicts intersections of 'sun, sea and skag', of affluence and poverty co-existing. Homelessness is both visible and invisible 'the place of many hiding places, some in full view'. Existing in such public spaces is not easy and subjects homeless people to ambivalence at best, but often violence and abuse (Farrugia, 2011). Yet these spaces also represent links to family and friends, spaces which retain meaning and resonance across time, representing 'the most special place' where my children and grandchildren are. Poetic inquiry can support a more person-centred approach (IFSW, 2012), allowing us to locate the experience of homelessness within a wider understanding of individual narrative and biography. This helps to balance homogeneous approaches which depict homelessness in a particular way, and illuminates the complex and nuanced experiences of individuals.

The relentless challenge of survival day by day permeates both poems depicted 
powerfully as 'the weight of Groundhog Day syndrome'. This gives insight into the perpetual grind involved in time passing slowly when you 'sleep and wake to the same conversations'. The structural challenges created by systems which create barriers is clearly evidenced in the poem 'Some People' where difficulties faced when trying to access benefits are graphically described.

These insights are important for social workers in terms of understanding homeless people more holistically, and providing an opportunity to enhance dialogue on important societal issues linked to inclusion and exclusion (Gergen and Gergen, 2011). Social work practice takes place with individuals and communities who have unique stories and needs. It is important to recognise the barriers which are created by systems which alienate individuals through ambivalence and disinterest. The repeated line 'to have people show concern then not even listen to your answer' is an important one for social work. It stresses the need for social workers to treat everyone with dignity and respect, and to develop awareness of how discourse and stereotypes about homelessness may get in the way of seeing the individual experience. It also reiterates the importance for social work to resist discourse that "unjustly places responsibility upon the shoulders of marginalised people and groups while obscuring systemic factors of oppression' (Shdaimah and McGarry, 2018, p. 34).

Arts-based research using poetry creates a 'space' for new understanding between the writer and audience. Collaborating with the performance poet allowed all phases of the research process to be imbued with a more creative way of expression, therefore disrupting 'our traditional modes of thinking and acting in analytical practice' (Coemans and Hannes 2017, p. 44). However, research with individuals who experience deep exclusion and experience chaotic lives is not easy. As the reflective diary extracts detail, attendance was often sporadic, and some individuals were disruptive or demanding. Fifteen participants contributed at various times during the ten poetry workshops, but sometimes no-one turned up. Attrition and poor attendance at research sessions are common features in research with certain vulnerable groups (Bonevski, et al., 2014; Johnsen, 2008). However, the reflective diary also depicts how participants also engaged during the sessions. When sessions were well attended they were described as a space for 'lively debate around the topics'. Participants appeared to relish the opportunity to explore language and imagery whilst shaping phrases and lines. A key output from the project has been a book of participant poetry around homelessness which is drawing attention to the challenges of living on the streets (Seldom Heard Voices, 2017). It is planned to use this as both a learning resource for social work students, as well as a wider resource for those interested in homelessness. Those from the hostel who contributed to the project, and could be found, were given copies of the poetry book. Informal feedback from participants was that this experience gave recognition of their lives and their work. Although taking part in the project did not find participants a home, the process acknowledged the human experience at the heart of homelessness (Pleace, 2016). 


\section{Conclusion}

This paper has considered how poetic inquiry can be used to create insights into lives lived in the half shadows. Such projects are not without challenge, as it may be difficult to recruit participants who experience challenging and ephemeral lives. As well as proving unique insights into the nuanced experiences of homeless individuals within a wider narrative, poetic inquiry can enable homeless people to collectively question society's attitudes and actions towards them, as well as allowing the audience to develop insights into the lived experience of life on the streets. Such an approach may also provide useful insights for social workers who seek to support individuals who experience multiple exclusions.

\section{Acknowledgements}

We would like to acknowledge the contributions of all those who participated in the project. The poetry book has the following reference ISBN 9781910616765.

\section{References}

Aykanian, A. and Lee, W. (2016) Social work's role in ending the criminalization of homelessness: Opportunities for action. Social Work, 61, 2, 183-185.

Bagley, C. and Castro-Salazar, R. (2012) Critical Arts-Based Research in Education: Performing Undocumented Historias. British Educational Research Journal, 38, 2, 239-260.

Bishop, E. C. and Willis, K. F. (2014) "Hope is that fiery feeling': Using poetry as data to explore the meanings of hope for young people. Forum: Qualitative Social Research, 15,1, Article 9 [Accessed at http://nbn-resolving.de/urn:nbn:de:0114-fqs140194]

Bonevski, B., Randell, M., Paul, C., Chapman, K., Twyman, L., Bryant, J., ... Hughes, C. (2014) Reaching the hard-to-reach: A systematic review of strategies for improving health and medical research with socially disadvantaged groups. BMC Biomedical Research Methodology, 14, 1-29.

Butler-Kisber, L. (2004) Poetic inquiry. Journal of Critical Inquiry into Curriculum and Instruction, 5, 1,1-4.

Butterwick, S. (2002) Your story/my story/our story: Performing interpretation in participatory theatre. Alberta Journal of Educational Research, 60, 3, 240-253.

Clarke, J., Febbraro, A., Hatzipantelis, M. and Nelson, G. (2005) Poetry and prose: Telling the stories of formerly homeless mentally ill people. Qualitative Inquiry, 11, 6, 913-932.

Clover, D. (2011) Successes and challenges of feminist arts-based participatory methodologies with homeless/street-involved women in Victoria. Action Research, 9, 1, 12-26. 
Coemans, S. and Hannes, K. (2017) Researchers under the spell of the arts: Two decades of using arts-based methods in community-based inquiry with vulnerable populations. Educational Research Review, 22, 34-49.

Ellard-Gray, A., Jeffrey, N.K., Choubak, M. and Crann, S.E. (2015) Finding the Hidden Participant: solutions for Recruiting Hidden, Hard-to-Reach, and vulnerable populations. International Journal of Qualitative Methods, 14, 5, 1-10.

Farrugia, D. (2011) Homeless youth managing relationships: Reflexive intersubjectivity and inequality. Young: Nordic Journal of Youth Research, 19, 4, 357-373.

Farrugia, D. and Gerrard, A. (2016) Academic Knowledge and Contemporary Poverty: The Politics of Homelessness Research. Sociology, 50, 2, 267-284.

Faugier, J. and Sargeant, M. (1997) Sampling hard to reach populations. Journal of Advanced Nursing, 26, 4, 790-797.

Fenge, L.A., Hodges, C. and Cutts, W. (2016) Performance poetry as a method to understand disability. Forum Qualitative Sozialforschung/Forum: Qualitative Social Research, 17, 2 [Accessed at http://www.qualitative-research.net/index.php/fqs/article/view/2464]

Finlay, S. (2000) Dream child: The role of poetic dialogue in homeless research. Qualitative Inquiry, 6, 3, 432-434.

Finlay, S. (2015) Embodied Homelessness: The Pros/Thesis of Art Research. Qualitative Inquiry, 21, 6, 504-509.

Fitzpatrick, S. (2005) Explaining Homelessness: A Critical Realist Perspective. Housing, Theory and Society, 22, 1, 1-17.

Fitzpatrick, S. (2007) Homelessness research initiative: a possible ESRC programme [Accessed at http:// www.homeless.org.uk/policyandinfo/research/ researchforum/researchprog/ index_html]

Fitzpatrick, S., Bramley, G. and Johnsen, S. (2013) Pathways into multiple exclusion: Homelessness in seven UK cities. Urban Studies, 50, 1, 148-168.

Fitzpatrick, S., Pawson, H., Bramley, G., Wilcox, S. and Watts, B. (2017) The homelessness monitor: England. Institute for Social Policy, Environment and Real Estate (I-SPHERE), Heriot-Watt University; City Futures Research Centre, University of New South Wales [Accessed at https://crisis.org.uk/media/236823/homelessness_monitor_england_2017. pdf]

Furman, R., Enterline, M., Thompson, R. and Shukraft, A. (2012) Poetry matters: A case for poetry in social work. Journal of Social Intervention: Theory and Practice, 21, 1, 5-17.

Gergen, K. J. and Gergen, M. (2011) Narrative inquiry: Dialogue beyond disciplines. In N. Bozatzis and T. Dragonas (Eds.) The discursive turn in social psychology Chagrin Falls, OH: Taos Institute Publications (pp. 120-128). [Accessed at http://www.taosinstitute.net/ Websites/taos/images/PublicationsWorldShare/DiscursiveTurn_f_v2.pdf]

Glesne, C. (1997) That rare feeling: Re-presenting research through poetic transcription. Qualitative Inquiry, 3, 2, 202-221.

Hesse-Biber, S. and Leavy, P. (2008) Introduction: Pushing on the methodologic boundaries. In S. N. Hesse-Biber and P. Leavy (Eds.) Handbook of emergent methods. New York: Guilford (pp. 1-15). 
Hodges, C.E., Fenge, L.A. and Cutts, W. (2014) Challenging perceptions of disability through performance poetry methods: the 'Seen but Seldom Heard' project. Disability \& Society, 29, 7,1090-1103.

International Federation of Social Work (IFSW) (2012) Statement of Ethical Principles [Accessed at http://ifsw.org/policies/statement-of-ethical-principles/]

Johnsen, S., May, J. and Cloke, P. (2008) Imag (in) ing 'homeless places': using auto photography to (re) examine the geographies of homelessness. Area, 40, 2, 194-207.

Jones, K. (2006) A Biographic Researcher in Pursuit of an Aesthetic: The Use of Arts-Based (Re)Presentations in 'Performative' Dissemination of Life Stories. Qualitative Sociology Review, 2, 1, 66-85.

Lahman, M.K., Geist, M.R., Rodriguez, K.L., Graglia, P.E., Richard, V.M. and Schendel, R.K. (2010) Poking around poetically: Research, poetry, and trustworthiness. Qualitative Inquiry, 16, 1, 39-48.

Liamputtong, P. (2007) Researching the vulnerable: A guide to sensitive research methods. London, England: SAGE.

McNiff, S. (2008) Arts-based research. In J. Knowles and A. Cole (Eds.) Handbook of the arts in qualitative research. Thousand Oaks, CA: Sage (pp. 29-40).

Moxley, D. (2014) Reflecting on the arts in social action: Possibilities for creative engagement in action learning. Action Learning Action Research Journal, 20, 1, 35-62.

Norman, T. and Pauly, B. (2013) Including people who experience homelessness: A scoping review of the literature. International Journal of Sociology and Social Policy, 3, 3-4, 136-51.

Oppong Asante, K. and Meyer-Weitz, A. (2015) Using reflective poems to describe the lived experiences of street children and adolescents in Ghana. International Journal of Adolescence and Youth, 20, 2, 148-150.

Pleace, N. (2016) Researching homelessness in Europe: Theoretical perspectives. European Journal of Homelessness, 10, 3, 19-44.

Rawdon, K. and Moxley, D. (2016) Connecting social work and activism in the arts through continuing professional education. Journal of Teaching in Social Work, 36, 4, 431-443.

Reeve, K. (2017) Welfare conditionality, benefit sanctions and homelessness in the UK: ending the 'something for nothing culture' or punishing the poor? Journal of Poverty and Social Justice, 25, 1, 65-78.

Seldom Heard Voices (2017) Seldom Heard Voices: Street Level Poetry. Dorset:.Honeybee Books.

Shdaimah C.S. and McGarry, B. (2017) Social workers' use of moral entrepreneurship to enact professional ethics in the field: case studies from the social justice profession. The British Journal of Social Work, 48, 21-36.

Shaghaghi, A., Bhopal, R.S. and Sheikh, A. (2011) Approaches to recruiting 'hard-to-reach' populations into research: a review of the literature. Health promotion perspectives, 1, 2, 86-94.

Sjollema, S.D., Hordyk , S., Walsh, C., Hanley, J. and Ives, N. (2012) Found poetry - Finding home: A qualitative study of homeless immigrant women. Journal of Poetry Therapy, 25, 4, 205-217.

Thomas, G.R., Kaiser, B.L. and Svabek, K. (2017) The Power of The Personal: Breaking Down 
Stereotypes and Building Human Connections. Narrative Inquiry in Bioethics, 7,1, 27- 30. Vandemark, L.M. (2007) Promoting the sense of self, place, and belonging in displaced persons: The example of homelessness. Archives of psychiatric nursing, 21, 5, 241-248.

Wacquant, L. (2010) Neo-liberal poverty governance: Race, place and the punitive turn in US welfare policy. Cambridge Journal of Regions, Economy and Society, 1, 17-36.

Wang, Q., Coemans, S., Siegesmund, R. and Hannes, K. (2017) Arts-based methods in socially engaged research practice: A classification framework. Art/Research International, 2, 2, 1-39. 